\title{
Endoscopic retrograde cholangiopancreatography (ERCP) for intradiverticular papilla: endoclip-assist- ed biliary cannulation
}

An intradiverticular papilla (IDP) can make biliary cannulation difficult during endoscopic retrograde cholangiopancreatography (ERCP), and endoscopists sometimes need to use special techniques to achieve deep common bile duct (CBD) cannulation [1 - 3]. We describe two difficult IDP cases in which successful biliary cannulation was achieved after using endoclips to facilitate a temporary change in the anatomical position of the major papilla.

A 56-year-old man underwent ERCP for CBD stones. On duodenoscopy, the major papilla was observed to be lying on the floppy mucosa, within the inferior rim of a diverticulum ( $\bullet$ Fig. 1 a). Although the papilla could be everted from the diverticulum using a catheter tip ( $\mathbf{F i g}$. $\mathbf{1}$ b), it would rotate back inside soon after the mechanical traction was withdrawn. This anatomical orientation prevented cannulation. An endoclip (Hx-600-135, Olympus Medical Systems Corp., Tokyo, Japan) was used to rotate the papilla externally and to fix it on the outside rim of the diverticulum. This procedure resulted in successful biliary cannulation ( $\bullet$ Fig. 1 c). A 77-year-old woman underwent ERCP for biliary sepsis with shock. On duodenoscopy, the small papilla could be identified on the left edge of the diverticulum only when the scope was advanced within the diverticulum ( Fig. 2a). Biliary cannulation was unsuccessful in this anatomical position. Therefore, two endoclips were applied to the inferior and lateral diverticular walls and the duodenal mucosa. This manipulation successfully everted and fixed the papilla on the diverticular margin ( $\bullet$ Fig. $\mathbf{2 b}$ ). The altered orientation allowed biliary cannulation to be carried out along the diverticular rim (॰ Fig. 2c).

Scotiniotis and Ginsberg reported the first case of successful treatment of IDP using endoclip-assisted biliary cannulation [4]. The satisfactory results obtained in our two cases confirm that this method can be added to the inventory for difficult biliary cannulation.

\section{Competing interests: None}

Endoscopy_UCTN_Code_TTT_1AR_2AB
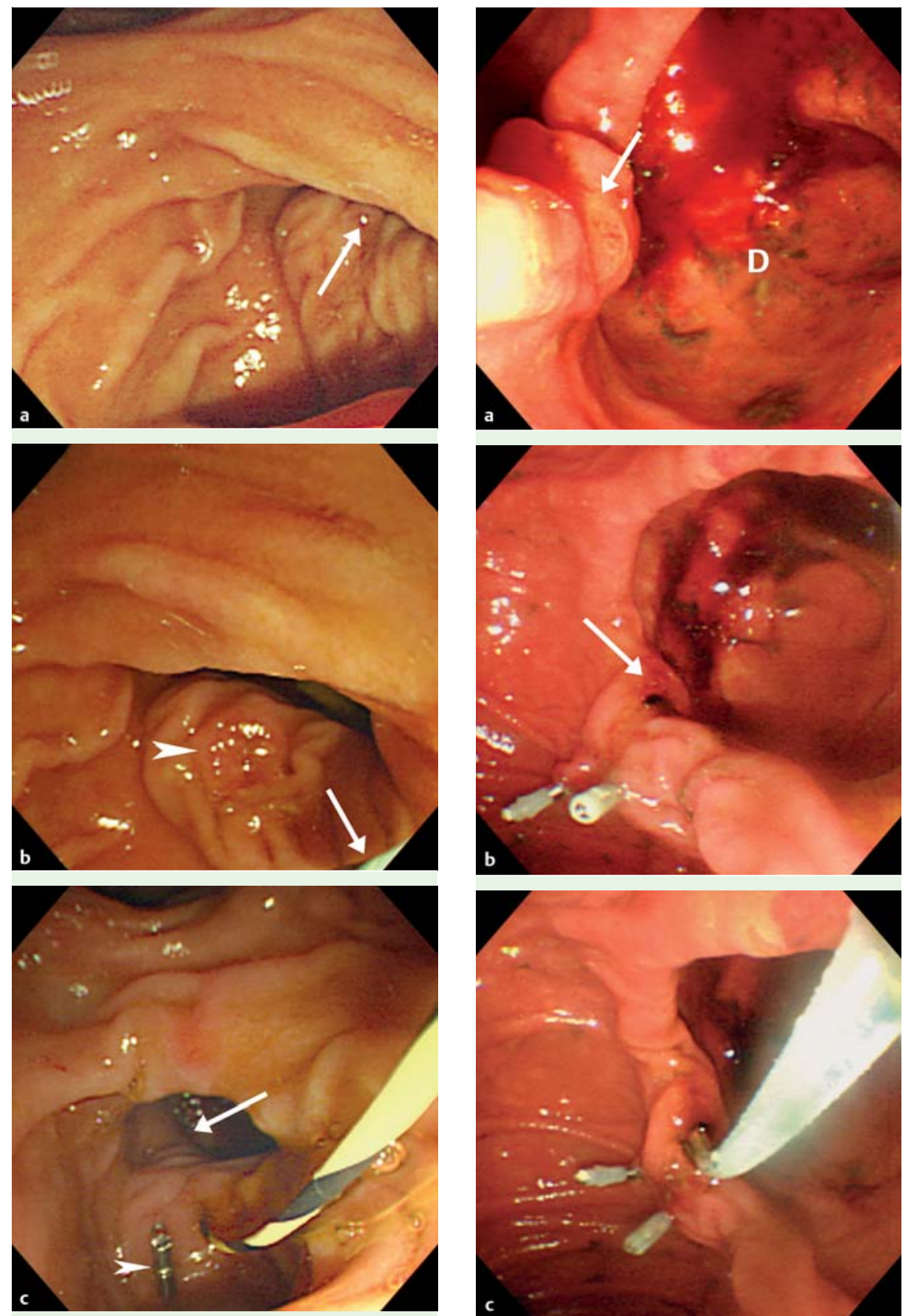

Fig. 1 a On duodenoscopy, the papillary frenulum (arrow) could be identified, but the papilla itself was completely hidden within the diverticulum. This anatomical orientation prevented cannulation. $\mathbf{b}$ Using a catheter tip (arrow), the floppy papilla (arrowhead) could be everted from the diverticulum. However, it rotated back soon after the catheter was withdrawn. c After endoscopic clipping (arrowhead), the papilla was rotated externally and fixed, and deep biliary cannulation was successfully carried out. Note the location of the distal common bile duct in the diverticulum (arrow).

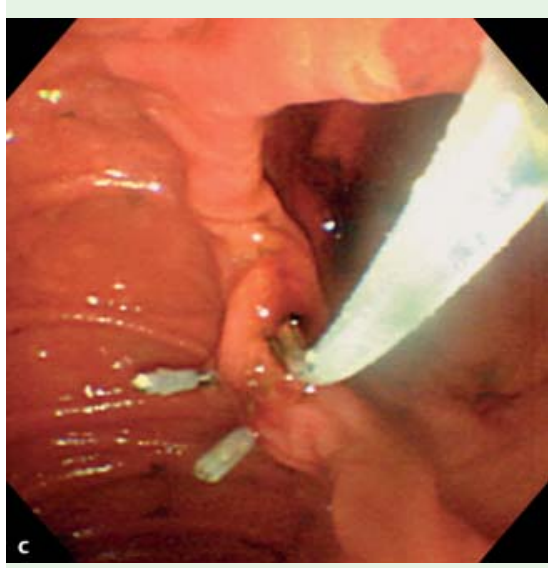

Fig. 2 a The small papilla (arrow) could only be identified when the scope was within the diverticulum (D). Bile duct cannulation was not possible in this situation. $\mathbf{b}$ With the help of two endoclips, the papilla (arrow) was everted and fixed on the diverticular margin. $\mathbf{c}$ Following reorientation of the papilla, deep bile duct cannulation was successfully carried out. 


\section{H. Huang, Y. K. Tsou, C. H. Lin,}

J. H. Tang

Department of Hepato-Gastroenterology, Chang Gung Memorial Hospital and Chang Gung University College of Medicine, Taipei, Taiwan

\section{References}

1 Lobo DN, Balfour TW, Iftikhar SY. Periampullary diverticula: consequences of failed ERCP. Ann R Coll Surg Engl 1998; 80: 326 331

2 Garcia-Cano J. ERCP cannulation of a hidden papilla within a duodenal diverticulum. Endoscopy 2008; 40S: E53

3 Lai R, Freeman ML. Endoscopic ultrasoundguided bile duct access for rendezvous ERCP drainage in the setting of intradiverticular papilla. Endoscopy 2005; 37: 487-489

4 Scotiniotis I, Ginsberg GG. Endoscopic clipassisted biliary cannulation: externalization and fixation of the major papilla from within a duodenal diverticulum using the endoscopic clip fixing device. Gastrointest Endosc 1999; 50: 431 - 436

\section{Bibliography}

DOI $10.1055 / \mathrm{s}-0029-1215008$

Endoscopy 2010; 42: E223 -E224

(c) Georg Thieme Verlag KG Stuttgart · New York . ISSN 0013-726X

\section{Corresponding author}

\section{J. H. Tang}

Department of Hepato-Gastroenterology, Chang Gung Memorial Hospital and Chang Gung University College of Medicine, Taipei, Taiwan

5 Fu-Shin Street

Kweishan

Taoyuan 333

Taiwan

Fax: +886-3-3272236

gima2239@adm.cgmh.org.tw 